\title{
Peculiarities of Math Students Adaptation to Temporary Forced Isolation or Quarantine
}

\author{
Elena I. Cherdymova ${ }^{1 *}$, Alfiya R. Masalimova ${ }^{2}$, Elmira R. Khairullina ${ }^{3}$, Dinara G. Vasbieva ${ }^{4}$, \\ Nupaisat P. Ismailova ${ }^{5}$, Rashad A. Kurbanov ${ }^{6}$, Andrey A. Tyazhelnikov ${ }^{7}$ \\ ${ }^{1}$ Samara National Research University named after Academician S.P. Korolev, Samara, RUSSIA \\ ${ }^{2}$ Kazan (Volga region) Federal University, Kazan, RUSSIA \\ ${ }^{3}$ Kazan National Research Technological University, Kazan, RUSSIA \\ ${ }^{4}$ Financial University under the Government of the Russian Federation, Moscow, RUSSIA \\ ${ }^{5}$ North-Caucasian Institute (Branch) of All-Russian State University of Justice (RPA of the Ministry of Justice or Russia), \\ Makhachkala, RUSSIA \\ ${ }^{6}$ Institute of Legislation and Comparative Law under the Government of the Russian Federation, Moscow, RUSSIA \\ ${ }^{7}$ I.M. Sechenov First Moscow Medical University (Sechenov University), Moscow, RUSSIA
}

Received 7 April 2020 - Accepted 6 August 2020

\begin{abstract}
The relevance of this article is determined by the need to study the difficulties facing young people in the process of social adaptation during quarantine on the back of the coronavirus pandemic. Due to their worldview that is often in conflict with the surrounding social environment, as well as their life attitudes and inability to adapt to the situation, young people may not be able to cope with all the processes of social adaptation that occur every now and then in everyday life. In the context of the quarantine announced to curb the spread of coronavirus, some young people may experience increased social maladaptation and develop psychosocial fears. This article is aimed at identifying the specifics of the relationship between adaptation strategies and disorders caused by social stresses in college students in the situation of temporary involuntary isolation (under quarantine). We used a questionnaire survey as a research methodology to identify both social adaptation strategies of math students and disorders associated with social stresses that they may develop in the situation of temporary involuntary isolation. The article has revealed strategies for the social adaptation of math students in the situation of quarantine. The article analyses the relationship between the social adaptation strategy and social stress disorders of math students during the coronavirus pandemic. The data obtained in this research can be used in social psychology, pedagogy, age psychology, medical psychology, as well as for further theoretical development of this problem.
\end{abstract}

Keywords: Math students, temporary involuntary isolation, coronavirus pandemic, quarantine, social stress disorders, social adaptation

\section{INTRODUCTION}

In a situation of temporary involuntary isolation, where an individual is isolated from other individuals as a result of the termination or dramatic reduction of usual social practices and ways of communication, in the context of drastic macro-social transformations associated with the coronavirus pandemic, social stress disorders develop in the entire population, including young people. The essential mental processes of late adolescence are the development of consciousness and self-awareness. Due to the development of consciousness, young people develop purposeful control over their attitudes towards the social environment and their activities (Ananyev, 1974; Gorshkov \& Sheregi, 2010; Volkov \& Volkova, 2010).

(c) 2020 by the authors; licensee Modestum. This article is an open access article distributed under the terms and conditions of the Creative Commons Attribution License (http://creativecommons.org/licenses/by/4.0/). 


\section{Contribution to the literature}

- It has been found that before the quarantine was announced to contain the coronavirus epidemic, more than half of math students rarely faced the need to adapt to various situations in life.

- It has been revealed that math students demonstrate a fairly high level of understanding of the need to adapt to the quarantine situation during the coronavirus epidemic.

- It has been found that in the situation of quarantine, more than half of the surveyed math students will employ a creative approach to the transformation of new conditions of life, which indicates the predominance of an active strategy among math students.

- It has been proved that in the situation of self-isolation, as the curriculum load increases, math students demonstrated a higher degree of irritation and a state of protest along with restrained emotional uplift and optimism.

- It has been proved that male math students mostly stated that they did not have depression, while female students demonstrated more frequent manifestations of anxiety and panic in the situation of quarantine announced in connection with the coronavirus pandemic.

- It has been found that the maths students resort to adaptive ways of relieving stress more often (sports, walking, socializing with friends in social media, or they enjoy being alone). An absolute minority of students resort to non-adaptive methods of stress relief (drinking alcohol). It has been revealed that male respondents are more inclined to cope with stress through sports and alcohol, while female respondents mostly like to walk, chat with friends in social media or be alone.

This age is characterised by such specific features as the development of independent logical thinking, imaginative memory, individual style of thinking, and interest in scientific research. The most important novelty formed in this period is self-education, i.e. selfcognition, the core element of which is the individual's self-attitude. An individual strives for self-identification as a person and as a human being involved in social production, in labour activity (Borisova \& Solodova, 1997; Cherdymova, 2019; Golovaty, 1999; Nemov, 1995; Sorokoumova et al., 2019). Notably, some young people begin to gravitate towards leadership as an upcoming activity. This category of individuals seeks to learn how to influence others and for this purpose studies social processes, consciously reflecting on them. The age in question is characterised by maximalist judgments and a kind of egocentric thinking; thus, developing their theories, young people behave as if the whole world obeys their theories and not vice versa (Pugach, 2001; Shchenina, 2005; Zimnaya, 1998). The desire to prove their independence and establish identity is accompanied by typical behavioural reactions, such as "scant regard" for the advice of elders, distrust, and criticism of older generations, and sometimes even explicit opposition. Thus, we can see that student life is a period of stabilisation of personality. During this period, an individual develops a stable worldview and understanding of his/her place in life. The essential process of this period is self-determination, both professional and personal (Kozina, 2010; Lisovsky, 1996; Volkova, 2001). These processes occur in modern students surrounded by a social environment that is exposed to some panic attacks associated with the coronavirus pandemic and is characterised as unstable by researchers.
Such an environment, which materialises during an epidemic, can only instill feelings of anxiety, discomfort, internal instability, uncertainty about the future, and a sense of insecurity. Aggravating social conditions during the coronavirus pandemic have led to a sharp expansion of neuropsychiatric and physical disorders, i.e. psychosomatic illnesses, that are to a large extent triggered by emotional factors (Isaev, 2005; Kelasyev \& Pervova, 2012; Korkina, Lakosina \& Lichko, 1995; Olkhovaya et al., 2019; Pushkarev et al., 2019; Semke, 1988; Usak et al., 2020). Most of the country's population actually experiences prolonged, or rather, chronic stress that is distinguished by such characteristics as totality, universality, and difficulties in verification. As a consequence, the quarantine announced in connection with the coronavirus epidemic can facilitate the development of the state of psychoemotional overstrain and mental maladaptation in plenty of people, which is essentially a collective trauma. The general characteristics of social stress disorders will be subject to the "inrush" of manifestations of social disruption in the lives of a huge number of people (Aliyev \& Aliyeva, 2010; Berezin, 1988; Dmitrieva \& Volozhin, 2001; Knyazeva \& Kurdyumov, 2002; Putilina et al., 2019).

In addition, along with global political and economic problems, an important place among the triggers of social stress disorders associated with quarantine announced in connection with the coronavirus pandemic may be held by individual problems such as the organisation of life, the inability to get motivated by individualistic and collectivistic values inherent in a particular group of people, and the relationship between emotional and rational principles. Most scientists agree that social stress disorders are the result of stress or overstrain caused by social factors, which leads to 
disorders developing in the process of adaptation (Makievskaya, 2010; Pankratieva, Popov \& Shilenko, 1989; Zhuravleva, 2010).

Through the prism of the interpretive paradigm, stress develops since in the situation of social upheavals the subject of adaptation, who is under quarantine announced in connection with the coronavirus pandemic, is unable to adequately assess the situation requiring adaptation, choose the goal of social adaptation, the means to achieve it, and the adaptation strategy.

Social stress disorders cause changes in the health and behaviour of an individual (Ananyev, 2006; Bogdanova, 2010; Gundarov, 2001; Samsonova, 2010). Prolonged social stress poses a threat to social health not only of an individual but also of the society as a whole. This can exact tragic toll, such as, for instance, depopulation of an entire country.

\section{MATERIALS AND METHODS}

In the course of an empirical research, 120 maths students of seven state Russian universities were surveyed: Samara National Research University named after Academician S.P. Korolev, Kazan (Volga region) Federal University, Kazan National Research Technological University, Financial University under the Government of the Russian Federation, NorthCaucasian Institute (Branch), All-Russian State University of Justice (RPA of the Ministry of Justice or Russia, Institute of Legislation and Comparative Law under the Government of the Russian Federation, I.M. Sechenov First Moscow Medical University (Sechenov University) - using the developed questionnaire. The survey was of an exploratory and pilot nature. Research objectives:

1. To describe the social adaptation strategies of modern students in the situation of temporary involuntary isolation (under quarantine).

2. To identify social stress disorders of maths students in the situation of temporary involuntary isolation (under quarantine).

3. To reveal the relationship between social adaptation strategies and social stress disorders in the situation of temporary involuntary isolation (under quarantine).

The research was conducted using a questionnaire that contained five blocks of questions:

1. Characteristics of social adaptation strategies used by respondents in the situation of quarantine.

2. Satisfaction with the results of social adaptation in the situation of temporary involuntary isolation (under quarantine);

3. Attitudes to social phenomena associated with a coronavirus that causes stress disorders;

4. The presence of signs of behaviour typical for social stress disorders;

\section{Social and demographic block.}

The obtained results were analysed using the SPSS statistical package.

The respondents' years of study: $1-19 \%, 2-27 \%, 3-$ $29 \%, 4-24 \%$, and $5-1 \%$. Age groups of respondents: $17-$ 20 years - $65 \%$ and $21-25$ years - 35\%. Among the respondents, $35 \%$ were male students, and $65 \%$ - female students. Marital status of respondents: registered marriage $-3.8 \%$, common-law marriage $-12 \%$, divorced - $1 \%$, single $-83 \%$. $98 \%$ of respondents do not have children, $2 \%$ have one child, $1 \%$ have 3 or more children.

\section{RESULTS AND DISCUSSIONS}

One of the objectives of our empirical research was to find out which strategy of social adaptation prevails among maths students in the situation of temporary involuntary isolation (under quarantine). Any real situation develops into an adaptive one if the individual recognises it as such. That's why it was important to establish how often students face situations that require adaptation during the quarantine period. According to the survey results, more than half of the respondents $(62 \%)$ rarely feel the need to adapt to life situations, more than a third of respondents (35\%) often feel this need, and $3 \%$ - never encounter such situations. The data obtained indicate a fairly high level of the respondents' awareness of the necessity to adapt to the situation of temporary involuntary isolation (under quarantine). There are no significant differences in the opinions of male and female maths students on this issue. Secondyear and third-year students answered that they less often felt the need to adapt to life situations. The latest data is largely determined by the different objective conditions faced by students of different courses. During the first year of study, students adapt to student life, while the fourth-year students face the need to plan their further life after graduation (since the number of the fifth-year respondents was quite small, the responses of these respondent group were not taken into account in the analysis of correlations).

An important component of the social adaptation strategy in the situation of quarantine declared in connection with the coronavirus epidemic is the model of the action algorithm, which is largely based on the stability of the individual's attitudes. The results of the survey showed that more than half of the maths students surveyed (70\%) said they had beliefs they would follow in any situation, $11 \%$ answered negatively, and 19\% neither agreed nor disagreed. There are no significant differences in the opinions on this issue between male and female students as well as students of different years of study. The data obtained provide an indirect indication that more than half of the respondents are ready to take active actions to quickly transform the environment; this does not depend on gender or the year 
of study. Probably, this intention to follow the beliefs was formed before they entered college.

Moral norms are an important component of a person's worldview attitudes that influence the choice of social adaptation strategies, especially in such extreme conditions of quarantine in the situation of temporary involuntary isolation (under quarantine). Thus, one in ten $(10 \%)$ would sacrifice the generally accepted norms of morality to achieve their goals, $34 \%$ could sacrifice it, if necessary, $47 \%$ - only in extreme cases, and only $8 \%$ said they would never compromise accepted norms, while the rest 3\% did not give a certain answer. Only $8 \%$ would never compromise commonly accepted moral norms to achieve their goals, while $3 \%$ did not give a certain answer. This probably indicates some flexibility in the behaviour of an individual in a situation of social adaptation, since the vast majority of maths students $(89 \%)$ in some circumstances can compromise the norms of morality. No significant differences in the opinions on this issue between male and female students were found. It was the fourth-year students who demonstrated the importance of moral norms to a greater extent. Thirteen per cent of the respondents said they would never be able to compromise ethical principles to achieve their goal.

A significant part of the surveyed maths students $(41 \%)$ have noted that they rely only on their own opinion when evaluating their life situation; this indicates that they independently analyse the reality. Twenty-four per cent of respondents rely on the opinion of their relatives, nine per cent - on the opinion of significant others; and for twenty-seven per cent, any opinion is important. Half of the male students (50\%) rely only on their own opinion in evaluating their life attitudes, which is above the average across the sample and $15 \%$ higher than the average among female students. At the same time, female students are more likely to rely on the opinion of relatives and significant others than male students ( $41 \%$; for male students this number is $23 \%$ ). These results indicate that male students demonstrate a higher level of independence in the analysis of the reality around them. When collecting the opinions of maths students of different years of study on this issue, the following trend has been revealed: firstyear students are more likely to focus on their own opinions (54\%), while fourth-year students have responded that any opinion is important to them (37\%).

To identify the optimal models of the respondents' action algorithm, we have proposed a projective question that simulates the situation of life under quarantine in the situation of temporary involuntary isolation (under quarantine). This is a kind of "critical" situation, since it will definitely be considered by the respondent as the one requiring adaptation. The proposed action algorithm models are projections of active, reactive, and combined strategies. More than half of the surveyed maths students (59\%) will employ a creative approach to transforming new living conditions, which indicates that an active strategy prevails. Thirty-six per cent will obtain everything necessary for survival, but will not radically transform anything, which characterises the chosen strategy as a combined one. Four per cent will not take active actions, which is a projection of a reactive adaptation strategy. No significant differences in the opinions on this issue between male and female students were found. First and third-year maths students more often demonstrate an active behaviour strategy, while second and fourth-year students are more inclined to show a combined strategy than others.

The flexibility of thinking and behaviour is an important prerequisite for successful adaptation to quarantine in a situation of the coronavirus pandemic. Respondents were offered a hypothetical situation of failure to adapt to quarantine and some options of behaviour in it. The vast majority of respondents $(84 \%)$ were ready to change their behaviour tactics, should they fail to achieve the goals set, $5 \%$ would give up, and $11 \%$ gave no certain answer. The data obtained provide an indirect indication of the predominance of a combined adaptation strategy. Male students (93\%) are more likely to change their behaviour tactics in case of failure than female students $(80 \%)$, while the latter more often fail to give a certain response ( $14 \%$ of female students and $5 \%$ of male students). Older maths students are more likely to encounter difficulties in answering $(18 \%)$ what they would do in case the chosen strategy does not bring the desired results.

Most of the respondents consider their experience of life in the situation of temporary involuntary isolation (under quarantine) as requiring adaptation. This indicates the relevance of our topic of research studied using this empirical object. We have revealed some signs pointing at the predominance of active components in the behaviour strategy. They manifest themselves through the intention to follow one's own beliefs in any situation, transforming the environment at one's discretion, and independent analysis of the situation. At the same time, a significant part of maths students can change their behaviour strategy, if they fail to achieve the desired results, and neglect established moral norms. These manifestations may indicate some flexibility of behaviour in the situation of temporary involuntary isolation (under quarantine), which is a sign of a combined strategy. On the other hand, there is a possibility of unscrupulous behaviour and disregard for moral norms. Our conclusions indicate the contradictory intentions and instability of worldview principles in such a difficult situation on the back of temporary involuntary isolation (under quarantine). This is quite understandable taking into account the age-specific characteristics of this group, namely, the fact that during this period an individual goes through the processes of character formation and stabilisation. 
Satisfaction with the results of social adaptation shows that they meet the initially set goal. The judgement as to whether the adaptation was successful is derived based on the individual's subjective assessment, i.e. the individual can consider an adaptive situation acceptable and comfortable, even if other circumstances are not favourable, and vice versa. Therefore, satisfaction with certain aspects of life is an indicator of successful adaptation. Personal opinions on the adaptation results in the course of the survey were revealed by assessing the degree of respondents' satisfaction or dissatisfaction with their health, financial situation, college experience, satisfaction of cultural wants, involvement in public life, and overall assessment of their emotional well-being.

Next, we will discuss the degree to which the maths students are satisfied with certain aspects of life in the situation of temporary involuntary isolation (under quarantine). Most of the respondents (79\%) have stated they are fully or partially satisfied with their health $(25 \%$ of them are completely satisfied). One in five (20\%) are partially or completely dissatisfied with their health, and $1 \%$ could not give a certain answer. No significant differences in the opinions on this issue between male and female students were found. The fourth-year students surveyed are less satisfied with their health $(32 \%)$ than younger students.

The results of the survey have shown that as students' progress to the next years of study, they feel more frustration and protest, while their enthusiasm and optimism decrease. In general, maths students are less optimistic by the third year of study, while among middle-years students (2nd and 3d) almost one in six has noted a predominantly neutral mood. The surveyed students have demonstrated mainly optimistic attitudes. However, as the students' progress to the next years of study, they feel more frustration and protest, while their enthusiasm decreases. This probably can be explained by the fact that as a person grows older, they regard a larger number of situations as adaptive and develop a system of personal attitudes, i.e. their worldviews become mature. Female maths students demonstrate more frequent manifestations of anxiety and panic in the situation of quarantine declared in connection with the coronavirus pandemic. Thus, $16 \%$ of the female students surveyed have noted frequent states of anxiety and panic, while this number among male students was $6 \%$; $15 \%$ of male and only $4 \%$ of female students have indicated they never experience such conditions. There are no significant differences in the responses among students of different years of study.

Depressive reactions are an important indicator of social stress disorders. When asked whether they experience such reactions, $87.8 \%$ of the surveyed students have given an affirmative response, indicating a different frequency, and $11 \%$ have answered in the negative.
Another important indicator of social stress disorders in the situation of temporary involuntary isolation (under quarantine) is the manifestation of anxiety and panic. The vast majority (92\%) of students experience anxiety and panic with varying frequency, of them $13 \%$ experience such reactions frequently and only $7 \%$ never. Frequent and occasional depressive reactions are more common for fourth-year students $(52.8 \%)$ compared to first-year students (41\%).

The group of the maths students, who participated in the survey and experience depressive reactions occasionally, consists to a larger extent of those prone to not following their beliefs in any situation.

The group of respondents believing that ordinary citizens cannot influence the processes taking place in the country includes a larger number of individuals who often experience depressive reactions, if compared to the group of respondents who have answered that ordinary citizens influence the political situation in the country.

The behavioural symptoms of stress include the "negative" nature of relief of accumulated tension, namely, drinking alcohol and reduced social contacts. According to the results of the survey, more than half of the respondents $(63 \%)$ still prefer "positive" ways to relieve tension, such as sports $(21 \%)$, walking and socializing with friends in social media (42\%), $21 \%$ like to be alone, $8 \%$ drink occasionally, and $8 \%$ gave no certain answer. The data obtained generally indicates quite a moderate level of stress. Male students are more likely to relieve stress through sports $(29 \%)$ and alcohol $(13 \%)$ (female students $-17 \%$ and $4 \%$, respectively). Female students are more prone to go for a walk, chat with friends in social media and be alone $(47 \%$ and $25 \%$, respectively), while the number of male students who have chosen these behavioural strategies is slightly less ( $35 \%$ and $13 \%$, respectively).

There are no significant differences in the number of maths students of different years of study who have answered that they relieve stress by drinking and being alone, which indicates a relatively stable level of respondents of different years of study who experience stress disorder in the situation of temporary involuntary isolation (under quarantine).

Loss of behavioural flexibility and reluctance to compromise are also a behavioural response to stress. The results of the survey have shown that only $0.6 \%$ of the surveyed maths students never compromise. More than half of the respondents (55\%) sometimes compromise, of which $29 \%$ do it often, $14 \%$ - rarely, and $2 \%$ have given no certain answer. There are no significant differences in the opinions on this issue between male and female students as well as students of different years of study. 


\section{CONCLUSION}

All communication between an individual and the society in the situation of quarantine on the back of the coronavirus pandemic occurs through the exchange of information. We rely on the assumption that there is a need for information, especially in the situation of temporary involuntary isolation (under quarantine), which manifests itself through the requirement that any activity and satisfaction of all other needs is preceded by the production, perception, and use of information suitable for selecting goals, determining means and optimizing efforts. In addition to individual features, the characteristics of the social environment in the situation of temporary involuntary isolation (under quarantine) are of great importance when choosing a specific adaptive strategy. An adaptive personality is flexible in choosing adaptive strategies; a non-adaptive personality is often unable to achieve adaptation appropriate in the current situation. Thus, social adaptation is considered as a process of an individual's informational and communicational interaction with the environment, in which the individual develops a model of behaviour in the situation of temporary involuntary isolation (under quarantine) in an effort to achieve the most favorable results. This is a cyclical process, and it can affect any sphere of an individual's life. Thus, the social adaptation strategy is the central element of social adaptation, which is the basis for the individual's adaptation. The concept of social adaptation strategy comprises general attitudes (conscious or unconscious) that guide an individual in the process of adaptation to social conditions. It includes the optimal model of the desired results and the optimal model of the action algorithm in the situation of temporary involuntary isolation (under quarantine). The social adaptation strategy is implemented through coping with adaptive situations in a specific social environment. We can distinguish such structural elements of the social adaptation strategy in the situation of temporary involuntary isolation (under quarantine) as a means to achieve the goal, worldview principles, and attitude to the adaptive situation. The social adaptation strategy can be implemented purposefully, rationally or spontaneously. Strategies can have active, reactive or combined nature, depending on how adequately and promptly an individual responds to changes in the social environment in the adaptive situation and whether he or she critically evaluates the available means to achieve their goals, as well as their abilities and available resources.

Other major triggers of stress disorders in the situation of quarantine on the back of the coronavirus pandemic include a dramatic change in social relationships that goes beyond the usual experience, a change in the system of cultural, ideological, moral, and religious beliefs, as well as norms and values that had remained unchanged throughout the life of previous generations, changes in social ties and life plans, instability and uncertainty of the life situation. Such social environment in the situation of temporary involuntary isolation (under quarantine) poses difficulties in the process of social adaptation, especially for young people with little social experience.

\section{ACKNOWLEDGEMENTS}

1. The work is performed according to the Russian Government Program of Competitive Growth of Kazan Federal University.

2. The work is performed according to the Program of Development of Financial University under the Government of the Russian Federation for 2020.

3. The publication has been supported by the 'Russian Academic Excellence Project 5 - 100' of the I M Sechenov First Moscow State Medical University (Sechenov University).

\section{REFERENCES}

Aliyev, K. D., \& Aliyeva, Yu. V. (2010). Depression as a Disease of the Future, Its Impact on the Economy and Social Structures. Nizhny Novgorod: NISOTS Publishing House.

Ananyev, B. G. (1974). Revisiting Psychology of Student Age. Modern Psychological Problems of Higher Education, 2, 39-52.

Ananyev, V. A. (2006). Fundamentals of Health Psychology. Conceptual Foundations of Health Psychology St. Petersburg: Rech.

Berezin, F. B. (1988). Psychical and Psychophysiological Adaptation of a Person. Leningrad: Nauka.

Bogdanova, T. V. (2010). Mental Health as a Resource. Health as a Resource. Nizhny Novgorod: NISOTS Publishing House.

Borisova, L. G., \& Solodova, G. S. (1997). Sociology of Personality. Novosibirsk.

Dmitrieva, T. B., \& Volozhin, A. I. (2001). Social Stress and Mental Health. Moscow: All-Russia Academic, Research and Methodology Centre of the Ministry of Health of the Russian Federation.

Golovaty, N. F. (1999). Sociology of Youth: Series of Lectures. Kyiv: MAUP.

Gorshkov, M. K., \& Sheregi, F. E. (2010). Youth of Russia: Sociological Portrait. Moscow: Center for Social Forecasting and Marketing.

Gundarov, I. A. (2001). Spiritual Distress and Demographic Catastrophe. Social Sciences and Modern Times, 5, 58-67.

Isaev, D. N. (2005). Emotional Stress, Psychosomatic and Somatopsychic Disorders in Children. St. Petersburg: Rech. 
Kelasyev, V. N., \& Pervova, I. L. (2012). Social Determinants of Health. Bulletin of Saint Petersburg University, 12(4), 182-189.

Knyazeva, Ye. N., \& Kurdyumov, S. P. (2002). Foundations of Synergetics. Modes with Exacerbation, Self-Organisation, Tempo Worlds. St. Petersburg: Aleteyya.

Korkina, M. V., Lakosina, N. D., \& Lichko, A. Ye. (1995). Psychiatry: Textbook. Moscow: Meditsina.

Kozina, G. Yu. (2010). High School Youth as a Strategic Resource for the Development of Modern Society. Nizhny Novgorod: NISOTS Publishing House.

Lisovsky, V. T. (1996). Sociology of Youth: Textbook. St. Petersburg: Publishing House of St. Petersburg University, 1996. p. 460.

Makievskaya, N. M. (2010). The Problem of Socially Significant Diseases Spreading Among Young People. Nizhny Novgorod: NISOTS Publishing House.

Nemov, R. S. (1995). Psychology: Textbook for Teacher Training College Students. Moscow: VLADOS, p. 195.

Olkhovaya, T. A., Cherdymova, E. I., Merculova, L. V., Manakova, O. S., Sukhodolova, E. M., Laptev, A. A., \& Popova, O. V. (2019). Development features of students' communicative focus. Modern Journal of Language Teaching Methods, 9(1), 78-89.

Pankratieva, N. V., Popov, V. F., \& Shilenko, Yu. V (1989). Health Is Social Value: Questions and Answers. Moscow: Mysl.

Pugach, V. F. (2001). Russian Students: Statistical and Sociological Analysis. Moscow: Research Centre for Professional Education Quality.

Pushkarev, V. V., Cherdymova, E. I., Prokopyev, A. I., Kochurov, M. G., Shamanin, N. V., Ezhov, S. G., Kamenskaya, S. V., \& Kargina, N. V. (2019). Motivation and needs in the area of spouses with different experiences of cohabitation. Dilemas contemporáneos: Educación, Política y Valores, 6(3), 4153.

Putilina, E. S., Cherdymova, E. I., Kurbanov, R. A., Belyalova, A. M., Shatskaya, I. I., Kobzeva, E. I., Zhuravleva, M. V., \& Meleshko, G. S. (2019). Ecological relationships in real and virtual environments: contact points. EurAsian Journal of BioSciences Eurasia J Biosci, 13, 1475-1480.

Samsonova, T. I. (2010). Social Health and Competence of the Younger Generation. Health as a Resource Nizhny Novgorod: NISOTS Publishing House.

Semke, V. Ya. (1988). Hysterical Reactions. AMN [Academy of Medical Sciences] of the USSR. Moscow: Meditsina.

Shchenina, O. G. (2005). Youth in Modern Russia. Retrieved from: https:/ / www.isras.ru/index.php? page_id=1198\&id=3480\&printmode

Sorokoumova, E. A., Cherdymova, E. I., Rezvantseva, M. O., Kochneva, L. V., Latysheva, V. V., \& Perkova, E. P. (2019). Environmental and Social Practices of Old Stuff Use and Disposal by Students. Ekoloji, 28(107), 5065-5069.

Usak, M., Masalimova, R. A., Cherdymova, I. E., \& Shaidullina, R. A. (2020). The new playmaker in science education: Covid-19. Journal of Baltic Science Education, 19(2), 180-185. https://doi.org/10.33225 /jbse/20.19.180

Volkov, B. S., \& Volkova, N. V. (2010). Age Psychology. Moscow: Vlados.

Volkova, Yu. G. (2001). Sociology of Youth: Study Guide. Rostov-on-Don: Phoenix.

Zhuravleva, I. V. (2010). Modern Problems of Adolescent Reproductive Health. Nizhny Novgorod: NISOTS Publishing House.

Zimnaya, I. A. (1998). Upbringing - The Problem of Modern Education in Russia. Moscow: Research Centre for Professional Education Quality.

\section{http://www.ejmste.com}

